\title{
Study of Cardiac Manifestations in Patients of HIV Infection - A Cross Sectional Study in a Tertiary Care Centre in South India
}

\author{
Shivakumar B.G. ${ }^{1}$, Thirumal K.T. ${ }^{2}$, Shashank Shastry ${ }^{3}$, Siddharth Gosavi ${ }^{4}$ \\ 1, 2, 3,4 Department of General Medicine, Jagadguru Jayadeva \\ Murugarajendra Medical College, Davangere, Karnataka, India.
}

\section{ABSTRACT}

\section{BACKGROUND}

Advances in diagnosis, treatment, monitoring of HIV infection and availability of antiretroviral drugs have led to improved survival of patients but this has resulted in manifestation of late-stage disease including cardiac manifestations. We wanted to evaluate the cardiac manifestations in HIV patients and correlate them with CD4 count.

\section{METHODS}

This one year eight months study was done from November 2017 to July 2019 in the Department of Medicine, JJM Medical College and Hospital. Prior to the commencement, ethical clearance was obtained. 100 consecutive patients presenting HIV infection with or without opportunistic infections were studied. Patients were subjected to complete blood count and lipid profile. Cardiac manifestations were assessed by electrocardiography and 2D echocardiography.

\section{RESULTS}

Majority of the patients were males (68\%) and the commonest age group was 51 to 60 years (31\%). The CD4 count was found to be 50 - 100 cells / cum in $46 \%$ and < 50 cells / cumm in $29 \%$ of the patients. Cardiac manifestations were present in $64 \%$ of the patients. Sinus tachycardia was the commonest cardiac manifestation observed on ECG (19 \%). The other prominent cardiac manifestations included XVII dilated cardiomyopathy (20\%), Regional Wall Motion abnormality (19\%), diastolic and systolic dysfunction was noted in $14 \%$, Pericardial effusion (8\%). Few patients had Pulmonary embolism (2\%) and Valvular Heart disease $(1 \%)$ Cardiac manifestations were significantly high in patients with CD4 count $<50 /$ cum $(\mathrm{p}=0.0025)$.

\section{CONCLUSIONS}

Patients with HIV infection are at higher risk of developing cardiac manifestations and reduced CD4 count poses maximum risk.

\section{KEY WORDS}

Acquired Immunodeficiency Syndrome; Cardiac Manifestations; Human
Corresponding Author: Dr. Shashank Shastry, Intern Medical Officer, Medical College Road, MCC B Block, Kuvempu Nagar, Davangere, Karnataka - 577004, India. E-mail: shashankshastry@gmail.com

DOI: $10.14260 / \mathrm{jemds} / 2020 / 816$

How to Cite This Article:

Shivakumar BG, Thirumal KT, Shastry $S$, et al. Study of cardiac manifestations in patients of hiv infection - a cross sectional study in a tertiary care centre in South India. J Evolution Med Dent Sci 2020;9(49): 3716-3720, DOI:

10.14260/jemds/2020/816

Submission 12-09-2020,

Peer Review 20-10-2020,

Acceptance 27-10-2020,

Published 07-12-2020.

Copyright (C) 2020 Shivakumar B.G. et al This is an open access article distributed under Creative Commons Attribution License [Attribution 4.0 International (CC BY 4.0)] 


\section{BACKGROUND}

Acquired Immunodeficiency Syndrome (AIDS), results from human immunodeficiency virus (HIV) infection. At present HIV infection is a global pandemic with cases reported from every country and presents serious public health problem in the developing countries, especially in India. ${ }^{1}$ Average prevalence rate in India is about $0.22 \%$ and it has the third largest HIV epidemic in world.

AIDS is characterized by acquired profound, irreversible immune suppression that predisposes the individual to multiple opportunistic infection, malignant neoplasm, and a progressive dysfunction of multiple organ system. AIDS can take from two to fifteen years to develop depending on the individual. $^{2}$

HIV can be suppressed by combination ART. ART does not cure HIV infection but controls viral replication within a person's body and allows an individual's immune system to strengthen and regain the capacity to fight with infections. However, its prolonged usage has brought with it some metabolic abnormalities which need evaluation. Treatment with potent ART has transformed HIV infection from a rapidly fatal disease into chronic illness.

Due to the longer survival of PLHA, the manifestations of late stage HIV infection are now being met with more commonly than before, which includes HIV related cardiac diseases. ${ }^{3}$ Although not fully recognized in the early days of HIV epidemic, cardiac involvement has been reported with increasing frequency in recent years. ${ }^{2}$ The prevalence of cardiac involvement in AIDS patients have been reported to range between $28 \%$ and $73 \% .^{2}$ Studies have suggested that HIV may exhibit a cardiac tropism. But the heart may also be affected by other opportunistic viruses, fungi, and protozoa. Cardiac disease associated with HIV may therefore be multifactorial and can be caused by infectious or neoplastic complications or their treatments, any of the established causes of cardiac disease in other patient populations, or by HIV infection of the myocardium itself. The cardiac diseases in HIV infections include pericardial effusion, left ventricular dysfunction, myocarditis, dilated cardio-myopathy, endocarditis, pulmonary hypertension, malignant neoplasm, coronary artery disease and drug related cardiotoxicity. ${ }^{2}$ It is increasingly common for HIV / AIDS patients to be seen by cardiologists, and cardiovascular disease in HIV / AIDS is becoming increasingly recognized in the developing world.4,5,6 Despite this, heart disease can be overlooked in HIV-positive patients, because symptoms of breathlessness, fatigue, and poor exercise tolerance are frequently ascribed to other conditions associated with HIV infection. ${ }^{7}$

Patients with HIV / AIDS and symptoms suggestive of cardiac disease represent a diagnostic and therapeutic challenge in clinical practice; An algorithmic, anatomic approach to diagnosis, localizing disease to the endocardium, myocardium and pericardium can be useful. An intimate knowledge of opportunistic infections affecting the heart, effects of ART therapy and therapy for opportunistic infections on the heart is needed to be able to formulate a differential diagnosis. Effects of ART therapy, especially protease inhibitors on lipid and glucose metabolism, and their influence on progression to premature vascular disease require consideration.

CD4 count is a well-established marker in the monitoring of disease. In the past, CD4 count was used to guide chemotherapy but this practice has been changed in accordance to the newer NACO Guidelines. Considering the above facts, the present study was planned to assess the various cardiac manifestations in patients with HIV infection and to correlate them with CD4 count.

The objectives of the present study were to study various cardiac manifestations in patients with HIV infection. To study the correlation of cardiac manifestations with CD4 count.

\section{METHODS}

The present study was conducted in the Department of Medicine, Bapuji Hospital and Chigateri Government Hospital, Davangere attached to JJM medical college, Davangere on HIV infected patients during the period of November 2017 to July 2019. The study design was cross sectional study during November 2017 to July 2019. Prior to the commencement, the ethical clearance was obtained from Institutional Ethics Committee, JJM medical college, Davangere. Informed consent was obtained for every patient. A total of 100 HIV positive patients were enrolled for the study.

\section{Inclusion Criteria}

- All HIV infected individuals with / without opportunistic infection.

\section{Exclusion Criteria}

- HIV patients suffering from.

- Congenital heart disease.

- Rheumatic heart disease.

- Hypertension.

- Diabetes Mellitus

- Ischemic heart disease

\section{Method of Collection of Data}

Demographic data such as age and sex were recorded. Patients were interviewed for chief complaints and physical examination was done. These findings were recorded on a predesigned and pretested proforma (Annexure II).

\section{Investigations}

The selected patients underwent the following investigations.

- HIV testing.

- $\quad$ CD4 count.

- Complete blood count.

- Electrocardiography.

- 2D Echocardiography.

- Coronary Angiography, Cardiac enzymes. 


\section{Procedure}

CD4 count was done for all patients using flow cytometry using a BD FACS Count system. The CD4 count was done using kits supplied by the National AIDS Control Organisation of India (NACO) to anti-Retroviral Therapy (ART) Centre. ECG was done on 12 lead surface ECG machine. All the patients were evaluated using $M$ mode and two-dimensional transthoracic echocardiography and colour flow doppler examination.

\section{Outcome Variables}

The ECG findings were noted. The 2D echocardiography findings were evaluated as for pericardial effusion, dilated cardiomyopathy, systolic / diastolic dysfunction, regional wall motion abnormalities, clot, vegetation, and ejection fraction.

\section{Statistical Analysis}

The data obtained was coded and entered in Microsoft Excel Worksheet. The categorical data was expressed as rates, ratios and proportions and comparison was done using chi-square test. The continuous data was expressed as mean \pm standard deviation (SD. A probability value ( $\mathrm{p}$ value)) of less than or equal to 0.05 was considered as statistically significant.

\section{RESULTS}

Patients age ranged from 26 to 77 years, maximum number of cases were in the age group of 51 to 60 that is 31 patients (31\%), between $41-50$ years 29 patients ( $29 \%)$, between $61-70$ years 17 patients (17\%), between 31-40 15 patients (15\%) below 30 years 4 patients ( $4 \%$ ) and more than 70 years 4 patients ( $4 \%$ ). The mean age of the study population was $42.97 \pm 11.07$ years. Out of 100 patients 68 (68\%) were males and 32 patients (32\%) were females, accounting a ratio of male to female 2.125:1. In the present study, we observed the duration of HIV infection varied from 1 month to 10 years. In 86 patients (86\%) duration was either 5 or less than 5 years. In 14 patients $(14 \%)$ it was more than 5 years. We observed 24 patients (24\%) were on the treatment with anti-retroviral drugs, remaining 76 patients (76\%) were not on ART.

In our study majority of patients that is 61 (61\%) presented with overlapping symptoms (like breathlessness, chest pain, edema, fever), 16 patients (16\%) presented only with breathlessness, followed by chest pain 9 patients $(9$ $\%)$, Cough 6 patients ( $6 \%$ ), fever 5 patients (5\%) and pedal edema 3 patients ( $3 \%)$

\begin{tabular}{|ccc|}
\hline CD4 Count (/ cumm) & No. of Cases & Percentage \\
\hline$<50$ & 29 & 29.0 \\
$50-199$ & 46 & 46.0 \\
$200-499$ & 25 & 25.0 \\
Total & $\mathbf{1 0 0}$ & $\mathbf{1 0 0 . 0}$ \\
\hline & Table 1. CD4 Count \\
\hline
\end{tabular}

Most of our patients who had presented had CD4 count in between 50 - 199 that is 46 patients ( $46 \%$ ), followed by 29 patients (29\%) had count of less than 50 and 25 patients (25 $\%$ ) had count of more than 200 - 499. (Table 1)

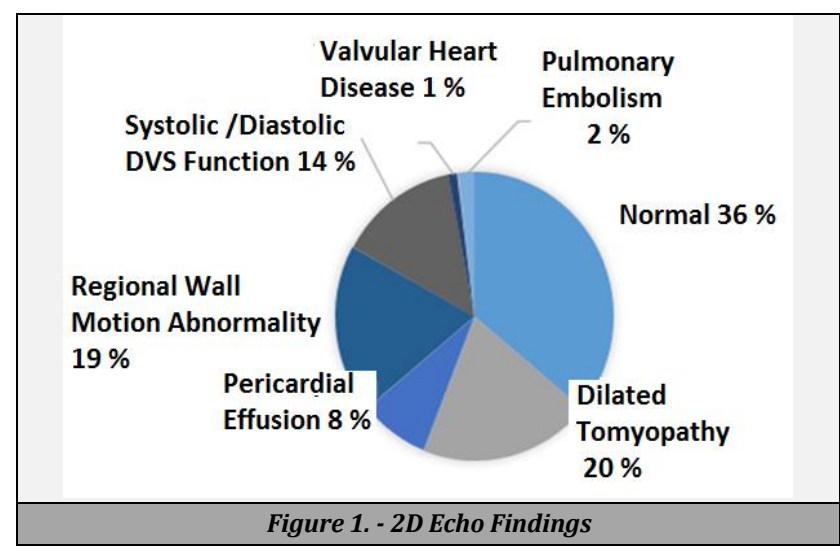

Figure 1 shows 2D Echocardiography findings of the study subjects. In 47 patients (47 \%) ECG tracing was normal, 24 patients (24\%) had sinus tachycardia, 19 patients (19\%) had evidence of Myocardial Infarction (13 patients Anterior wall MI, 6 patients-Inferior wall MI), 5 patients (5\%) had Low Voltage complexes 3 patients (3 had left ventricular hypertrophy and another patient atrial fibrillation. (Table 2).

\begin{tabular}{|ccc|}
\hline Finding & Cases & Percentage \\
Normal & 47 & $47 \%$ \\
Sinus tachycardia & 24 & $24 \%$ \\
Myocardial Anterior wall MI & 13 & $13 \%$ \\
Inferior wall MI & 6 & $6 \%$ \\
Left Ventricle Hypertrophy & 3 & $3 \%$ \\
LVC & 5 & $5 \%$ \\
AFib & 1 & $1 \%$ \\
Total & $\mathbf{1 0 0}$ & $\mathbf{1 0 0} \%$ \\
\hline \multicolumn{2}{c}{ Table 2. ECG Findings } \\
\hline
\end{tabular}

\begin{tabular}{|cccccccc|}
\hline \multirow{2}{*}{ Duration } & \multicolumn{1}{c}{ Present } & \multicolumn{2}{c|}{ Absent } & Total & $\%$ \\
& No. & $\%$ & No. & $\%$ & & \\
$\leq 5$ years & 3 & 30 & 7 & 70 & 10 & 100 \\
$>5$ years & 7 & 50 & 7 & 50 & 14 & - \\
Total & $\mathbf{1 0}$ & $\mathbf{4 1 . 7}$ & $\mathbf{1 4}$ & $\mathbf{5 8 . 3}$ & $\mathbf{2 4}$ & $\mathbf{1 0 0}$ \\
\hline Table 3. Coronary Angiography (Number = 19; in MI Patients) \\
\hline
\end{tabular}

\begin{tabular}{|c|c|c|c|c|c|c|}
\hline \multirow{3}{*}{ Duration } & \multicolumn{6}{|c|}{ Cardiac Manifestations without ART } \\
\hline & \multicolumn{2}{|c|}{ Present } & \multicolumn{2}{|c|}{ Absent } & \multirow{2}{*}{ Total } & \multirow{2}{*}{$\%$} \\
\hline & No. & $\%$ & No. & $\%$ & & \\
\hline 5 yrs. or less & 42 & 55.3 & 34 & 44.7 & 76 & 100 \\
\hline More than 5 yrs. & - & - & - & - & - & - \\
\hline Total & 42 & 55.3 & 34 & 44.7 & 76 & 100 \\
\hline \multicolumn{7}{|c|}{$\begin{array}{l}\text { Table 4. Correlation of Cardiac Manifestations with Duration of HIV } \\
\text { Infection without Treatment (ART) }\end{array}$} \\
\hline
\end{tabular}

In 19 patients who had presented with Myocardial Infarction, CK-MB was elevated in 17 patients and in 2 patients it was normal. All 19 patients had elevated levels of Troponin I. 17 out of 19 patients of myocardial infarction were subjected to Coronary Angiography and found to have 12 patients had single vessel disease, 5 had double vessel disease. We observed 10 patients who had infection of 5 years or less on treatment, 3 had cardiac abnormalities, 7 patients did not. Whereas 14 patients who had infection of $>5$ years on treatment, 7 patients showed cardiac abnormalities, 7 patients did not. ( $p$-value $=0.33$ being statistically 
insignificant). In patients with infection of 5 years or less without treatment (ART), 42 patients showed cardiac abnormalities, 34 patients did not. We did not get any patient with more than 5 years duration of illness without ART treatment. (Table 4)

Cardiac manifestations were compared with CD4 counts. In patients less than 50 count abnormalities were found in 20 patients and in 9 patients no abnormalities. Counts between 50 - 199, 24 had manifestation and 22 did not have. In patients with CD4 between 200 - 499, 8 had manifestation and 17 did not have. Correlation of cardiac manifestation with CD4 count had a significant $p$ value $(p$ value $=0.0025)$. (Table 5 )

\begin{tabular}{|c|cccccc|}
\hline \multirow{2}{*}{$\begin{array}{c}\text { CD4 Counts (/ } \\
\text { cumm) }\end{array}$} & \multicolumn{7}{c|}{ Present } & \multicolumn{7}{c|}{ Absent } & Total & \% \\
& No. & $\mathbf{\%}$ & No. & $\%$ & & \\
\hline$<50$ & 20 & 69.0 & 9 & 31.0 & 29 & 100.0 \\
$50-199$ & 24 & 52.2 & 22 & 47.8 & 46 & 100.0 \\
$200-499$ & 8 & 32.0 & 17 & 68.0 & 25 & 100.0 \\
Total & $\mathbf{5 2}$ & $\mathbf{5 2 . 0}$ & 48 & $\mathbf{4 8 . 0}$ & $\mathbf{1 0 0}$ & $\mathbf{1 0 0 . 0}$ \\
\hline Table 5. Correlation of Cardiac Manifestations with CD4 Count \\
\hline
\end{tabular}

Attempt to compare mean CD4 count with cardiac manifestation showed cardiac abnormalities present in 107.1 \pm 96.1 , absent in $148.1 \pm 109.1$. Statistically $p$ value was significant $(p=0.024)$. (Table 6)

\begin{tabular}{|ccccc|}
\hline $\begin{array}{c}\text { Cardiac } \\
\text { Manifestations }\end{array}$ & No. of Cases & \multicolumn{2}{c|}{ CD4 count } & \multirow{2}{*}{ P Value } \\
\hline Present & 52 & 107.1 & 96.1 & \\
Absent & 48 & 148.1 & 109.7 & 0.024, S \\
\hline Overall & 100 & 126.8 & 104.4 & - \\
\hline Table 6. Comparison of Mean CD4 Count with Cardiac Manifestations \\
\hline
\end{tabular}

\section{DISCUSSION}

In the present study of 100 patients with HIV infection, different cardiac manifestations were observed and same was compared with various factors. The duration of HIV infection varied from 1 month to 10 years. Maximum number of patients were 86 (86\%) with a duration, either five years or less than five years. Only 14 patients (14\%) duration was more than 5 years. It is difficult to state whether duration of HIV infection has direct bearing on cardiac manifestations owing to small sample size of 100 in our study.

The clinical presentations in our patients, majority i.e. 61 patients (61\%) had one or the other overlapping symptoms (like breathlessness, chest pain, edema, fever) followed by isolated symptoms of breathlessness 16 patients (16\%) chest pain 9 patients ( $9 \%$ ), Cough 6 patients ( $6 \%$ ), fever 5 patients (5\%) and pedal edema 3 patients (3\%).

When attempt was made to compare our study with various lab parameters, we observed following factors; In majority of our patients CD4 count was in between 50 - 199 i.e., 46 patients ( $46 \%$ ), less than 5029 patients ( $29 \%$ ), CD4, 25 patients ( $25 \%$ ) had CD4 count between $200-499$. Similar observation was made by Das et al. ${ }^{8}$ The low CD 4 count in our study was probably due to advanced disease state as all our patients were admitted cases in hospital.

ECG findings revealed normal tracing in 47 patients (47 $\%$ ), 22 patients ( $22 \%$ ) had sinus tachycardia, 19 patients (19
$\%)$ had evidence of Myocardial Infarction (13 patients Anterior wall MI, 6 patients - Inferior wall MI), 5 patients (5\%) had Low voltage complexes, 3 patients (3\%) 1 had left ventricular hypertrophy, other patient atrial fibrillation.

A study by Anita B et al $^{9}$ in their patients, sinus tachycardia was observed in $72 \%$; Study by Herdy GV et al ${ }^{10}$ had normal tracing in $33 \%$ and ST-T changes in $37 \%$ : Study by Hadadi et al11 observed $9.7 \%$ ST-T changes.

Echocardiographic evaluation of these 100 patients, normal study was observed in $36 \%$. In remaining $64 \%$ of patients, various cardiac abnormalities were observed. Dilated cardiomyopathy-20, Regional wall motion abnormality-19, Systolic / diastolic dysfunction-14, pericardial effusion-8, Valvular pathology-1, pulmonary embolism-2.

Various studies done by Das et al, ${ }^{8}$ Aggarwal et al (India) and Hakim et al ${ }^{12}$ in Zimbabwe, similar cardiac abnormalities were observed with varying percentage related to cardiac abnormalities.

In studies done by different researchers, pulmonary embolism is less reported. One study done by Howling et $\mathrm{al}^{13}$ reported incidence of $0.26 \%$. We observed in 2 of our patients' pulmonary embolism which was confirmed by gold standard investigation-pulmonary angiography. Reason for this in these HIV patients is little difficult to explain and needs further evaluation in our patients.

As it is known number of abnormalities of coagulation have been described in patients of HIV infection the most common is caused by lupus anticoagulant which is found in almost $60 \%$ of patients and may be associated with major thromboembolic phenomena. Other coagulation abnormalities that can occur in patients of HIV infection include anticardiolipin antibodies and reduced levels of active protein S. Some opportunistic infections particularly Cytomegalovirus and Herpes simplex virus may be responsible for the prothrombotic states by converting vascular endothelial cells from a noncoagulative to a procoagulative phenotype leading to expression to procoagulant phospholipids.

All our 19 patients of Ischemic heart disease (Anterior wall MI-13, Inferior wall MI-6) had cardiac enzyme abnormalities

Mary-Krause M, et al. ${ }^{14}$ and Klein D et al. ${ }^{15}$ observed an increased incidence of myocardial infarction in their patients. Also noted it is more common with patients on treatment with protease inhibitors although in our study none of our patients were on protease inhibitors. 17 out of 19 patients in our study were subjected to Coronary Angiography, 12 patients had single vessel disease, 5 had double vessel disease. Similar observation was made by Hsue PY et al ${ }^{16,2}$ who also observed coronary artery abnormalities (blocks). In his study most of the patients had single vessel disease.

In 10 patients with duration of HIV infection less than 5 years on treatment with ART, 3 patients had cardiac abnormalities whereas 7 patients did not have. In patients with more than 5 years duration of HIV infection on treatment (ART) 7 patients had cardiac abnormalities and 7 patients did not have cardiac abnormalities. In patients without treatment (ART), duration of HIV infection less than 5 years 42 patients had cardiac manifestations and 34 patients did not have. In our study we did not find any patients with duration of more than 5 years without treatment.

We observed taking into consideration duration and treatment with or without ART, in both these groups there 
were patients with cardiac involvement and without cardiac abnormalities. It is difficult to state the facts observed in these patients. This may be owing to small sample size, duration being less than 5 years or more than 5 years of HIV infection, with or without treatment. Finally, comparison of cardiac manifestations with CD4 count was attempted. In patients less than 50 count abnormalities were found in 20 patients and in 9 patients no abnormalities. Counts between 50 - 199, 24 patients had manifestation and 22 patients did not have. Counts between $200-499,8$ patients had manifestation and 17 did not have ( $p$ value $=0.0025$; statistically significant $)$

When mean CD4 count was considered there was a positive correlation between mean CD4 count and cardiac manifestation. ( $p=0.024$; statistically significant) Similar observation was made by Aggarwal et al.

The comparison of CD4 count by various authors has shown cardiac abnormalities increase with the level of immunosuppression and low CD4 count which is also observed in our study.

It has become easier in the recent years to find various cardiac abnormalities in patients with HIV infection because of availability of sophisticated investigations routinely in most of hospitals / centers.

The various cardiac abnormalities observed in our small sample size of 100 patients is little difficult to explain, it could be direct HIV infection, may be opportunistic infection, progressive disease state or may be ART drug toxicity, needs to be addressed by detailed study and large sample size.

\section{CONCLUSIONS}

There was a positive correlation with low CD4 count and mean CD4 count ( $p$ value being statistically significant). In patients with other variables like duration of infection, treatment with ART we found no correlation ( $p$ value being statistically insignificant). In our study, cardiac manifestations were seen in $57 \%$. This was possible because of availability of 2D echocardiography. It is necessary to further evaluate these patients to find out the exact reasons for various cardiac abnormalities.

We feel it is worth to study by adjusting the co-morbid conditions / confounding factors and comparing the cardiac abnormalities by detailed studies including histopathological studies which may determine as to whether these abnormalities are because of HIV infection and whether they are affected by factors like age, sex, duration of HIV and treatment with ART.

Sample size (100 patients) large sample size was a limitation of our study.

Data sharing statement provided by the authors is available with the full text of this article at jemds.com.

Financial or other competing interests: None.

Disclosure forms provided by the authors are available with the full text of this article at jemds.com.

\section{REFERENCES}

[1] Jagdish C, Varsha G, Manpreet K, et al. Clinicoepidemiological profile of human immunodeficiency virus infection over a period of 3 years in a North Indian tertiary care hospital. Indian J Med Microbiol 2013;31(3):316.

[2] Longo D, Fauci A, Kasper D, et al. Harrison's Principles of Internal Medicine. 18 $8^{\text {th }}$ edn. McGraw-Hill Professsional 2011:1506-87.

[3] Kaul S, Fishbein MC, Siegel RJ. Cardiac manifestations of acquired immune deficiency syndrome: a 1991 update. Am Heart J 1991;122(2):535-44.

[4] Ntsekhe M, Hakim J. Impact of human immunodeficiency virus infection oncardiovascular disease in Africa. Circulation 2005;112(23):3602-7.

[5] Bonow RO, Mann D, Zipes D, et al. Braunwald's Heart disease. $9^{\text {th }}$ edn. Philadelphia: Elsevier Saunders 2014.

[6] Fuster V, O'Rourke R, Walsh R, et al. Hurst's the Heart. 12 ${ }^{\text {th }}$ edn. New York: McGraw-Hill Professional 2007.

[7] Currie PF, Jacob AJ, Foreman AR, et al. Heart muscle disease related to HIV infection: prognostic implications. BMJ 1994;309(6969):1605-7.

[8] Singh A, Das S, Dalai RK. Study of cardiac manifestations in patients with HIV infection and their correlation with CD4 count in Indian population. International J Clin Med 2012;3(3):178-83.

[9] Anita B, Kakrani GP, Hiremath MS. Cardiac dysfunction associated with HIV infection. J Assoc Physicians India 2003;51:1182.

[10] Herdy GV, Ramos R, Bazin AR, et al. Clinicopathologic correlation in 50 cases of acquired immunodeficiency syndrome. Retrospective study. Arq Bras Cardiol 1994;62(2):95-8.

[11] Hadadi A, Badie SM, Rohamm M, et al. Prevalence of cardiac manifestations in HIV- infected patients in Iran. J Acquir Immune Defic Syndr 2010;55(1):e1-2.

[12] Hakim JG, Matenga JA, Siziya S. Myocardial dysfunction in human immunodeficiency virus infection: an echocardiographic study of 157 patients in hospital in Zimbabwe. Heart 1996;76(2):161-5.

[13] Howling SJ, Shaw PJ, Miller RF. Acute pulmonary embolism in patients with HIVdisease. Sex Transm Infect 1999;75(1):25-9.

[14] Mary-Krause M, Cotter L, Partisani M, et al. Impact of protease inhibitor treatment on myocardial infarction in HIV infected men. In: $8^{\text {th }}$ conference on retro virus and opportunistic infections. Chicago 2001: 4-8.

[15] Klein D, Hurley LB, Quesenberry CP, et al. Do protease inhibitors increase the risk for coronary heart disease in patients with HIV-1 infection? J Acquir Immune Defic Syndr 2002;30(5):471-7.

Hsue PY, Giri K, Erickson S, et al. Clinical features of acute coronary syndromes in patients with human immunodeficiency virus infection. Circulation 2004;109(3):316-9. 